\title{
The Biomechanics of the Diabetic Foot
}

\author{
Dennis Shavelson \\ The Foot Typing Center,NYC, Outreach Program, Surgical Attending, \\ Department of Podiatry, Wyckoff Heights Medical Center, Member, New York \\ Presbyterian Healthcare System, Brooklyn, New York \\ USA
}

\section{Introduction}

The importance of the physician's role in examining and assessing the diabetic foot is hard to overstate. ${ }^{1-2}$ Fifteen percent of the 16 million diabetic patients in the United States will develop foot ulcers. ${ }^{3,4}$ The diabetic foot is responsible for more than half of the 67,000 annual non-traumatic lower extremity amputations in the developed world. ${ }^{5}$ Lower extremity amputation is 15 times more likely to occur in a patient with diabetes. ${ }^{6}$ The annual cost of amputations is $\$ 600$ million and lost wages and morbidity are estimated at $\$ 1$ billion, annually. ${ }^{7}$ Finally, studies have shown that primary care physicians are rarely performing foot examinations on their diabetic patients during routine visits. ${ }^{8}$

The underlying reasons that the foot is the number one location for comorbidities in diabetes places peripheral neuropathy and its sequellae that include Loss of Protective Sensation (LOPS) and Loss of Proprioception atop the list ${ }^{9}$ with Peripheral Arterial Disease (PAD) ranking a distant second. These risk factors magnify preexisting biomechanical risk factors that function in closed chain (Table 1) into often overlooked loss of balance, function, productivity and quality of life that precede or are adjacent to the more obvious presentations of wounds, infections, hospitalizations and amputations that are, in reality, end stage events for more and more diabetic patients.

\begin{tabular}{|ll|}
\hline 1. & Ground Reactive Forces \\
\hline 2. & Hard, Unyielding Shoes \\
\hline 3. & Underlying Biomechanical Pathology \\
\hline 4. & Body Mass and Weight \\
\hline 5. & Activity Level \\
\hline 6. & Fitness Level \\
\hline 7. & Health State \\
\hline
\end{tabular}

Table 1. Underlying Biomechanical Risk Factors In Diabetes

Podiatry, as a profession and by degree, is the only profession armed with an underlying Functional Lower Extremity Biomechanics (FLEB) core. Three years of Undergraduate FLEB courses followed by up to three years of Residency that includes applying biomechanics to non operative and surgical decisions and the chief complaints of diabetic patients. This is 
then followed by Continuing Medical Education and most importantly, every Doctor of Podiatric Medicine (DPM) has an Evidence Based Practice Rooted in Biomechanics that includes orthotics and active and passive therapies that have been practiced for generations by the podiatric community.

It is my opinion that the medical community, weak in closed chain medicine, is not prepared to diagnose, treat and manage their patients biomechanically. This single fact is the reason that Podiatry plays such an important role in the medical community and the life of every diabetic.

\section{Biomechanics of the foot}

Definition: Biomechanics is the art and science of applying the scientific laws of Physics, Architecture, Engineering and Mechanics principles to living subjects. Although not a pure science and therefore, difficult to research and quantify, committed practitioners of Functional Lower Extremity Biomechanics (FLEB) have prepared themselves to conduct interpersonal practices by amassing foundational knowledge, professional experience and use the applicable evidence that has surfaced to produce, for each practitioner, his/her version of an Evidence Based Biomechanics Practice ${ }^{10-13}$.

Unlike pure science that focuses on inanimate objects, living subjects often do not obey Primary Scientific Laws. This is offset by the Biomechanical Literature which contains over 200 additions providing evidence that foot orthotics work ${ }^{14-18}$ in addition to continued research and study being called for and conducted but like other aspects of medicine, such as foot surgery, biomechanics remains as much an art as a science ${ }^{19-20}$. The Podiatry community has accepted as its responsibility, the closed chain foundation of our functional lives and in the case of the diabetic population, sits as educators, mentors and front line practitioners as no other specialist can when it comes to biomechanics and Closed Chain Medicine.

Understanding the biomechanics of the foot is an important component in the evaluation of the diabetic foot probably deserving greater focus than it has received. The successful compensation of underlying foot type-specific biomechanical pathology cannot be underestimated as one of the most important adjacent preventive and treatment models in the health history of the diabetic.

FLEB focuses on the human body from the low back down, in closed chain (standing [stance] or active [gait] and weighted upon the ground. Alternatively, Allopathic Medicine studies subjects in open chain kinetics (on an examining table or not weighted) ${ }^{21}$.

The etiological forces that must be overcome in managing a patient biomechanically can be reviewed using Table 1 . Since they differ for each individual, unless a patient encounter during which a biomechanical evaluation is performed as well as a historical interview to assess coexisting etiological factors is performed by a biomechanically oriented Podiatrist, the resultant orthotic and treatment plan may fall short of its potential benefits.

Removing pathological forces from the weightbearing surface of the foot, balancing and supporting the posture, leveraging the muscle-tendon units and training them to perform and providing functional and safe footwear for the diabetic foot are the biomechanical keys 
to preventing and treating foot ulcers, gait and balance problems and neuropathic foot syndromes. The use of straps, pads, foot orthotics, muscle strengthening and training programs and therapeutic footwear before considering surgery has been shown to reduce foot ulcers, foot infections, amputation and hospitalizations in a diabetic population while allowing the patient to maintain and improve walking and active functioning with a high level of efficiency and minimal injury and disability22.

The Biomechanical Anatomy of the Foot. Biomechanically, the foot can be divided into functional segments in two main ways. The first divides it at the Midtarsal Joint into a rearfoot and forefoot and the second divides the foot at the second and third rays into medial and lateral arch segments (Figure 1).

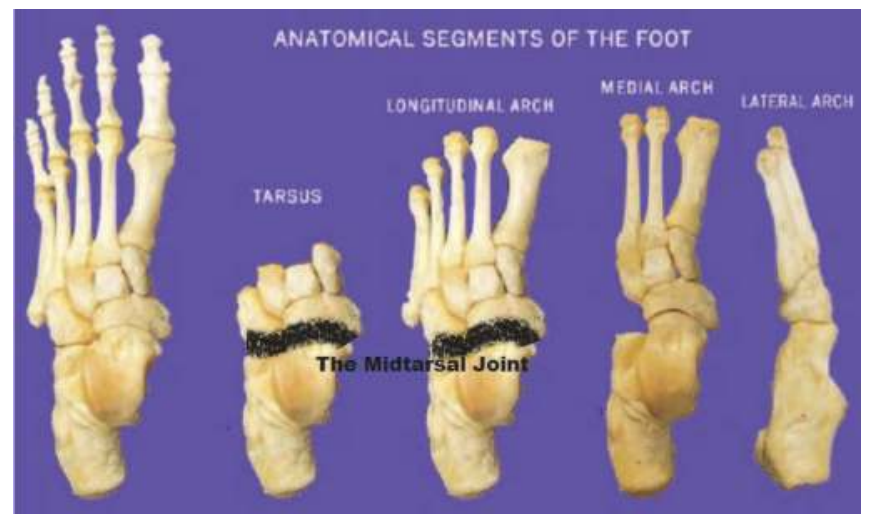

Fig. 1. Functional anatomy of the foot. (Adapted from Glick JB. Dynamics of the foot in locomotion. Pod Management 4:136, 2001, with permission).

The medial arch is composed of the calcaneus, talus, navicular, the three cuneiforms and the first, second and third metatarsals. The lateral arch is composed of the calcaneus, the cuboid and the fourth and fifth metatarsals. ${ }^{9}$ These two arches are connected by a transverse roof of bone. The surface underneath these osseous supports, architecturally, is known as The Vault of The Foot (Figure 2).23 This Vault, when centered and supported by healthy soft tissues, provides a lifetime foundation for upright weightbearing and function. In contrast if The Vault is allowed to become off-centered exhibiting excess stiffness, flexibility, collapse or arch, on a case to case basis, the resulting stressful compensations in pedal and postural bones, joints, muscles, tendons, ligaments and integumentary organs provides an ever increasing burden to society as we live longer and more active lives.

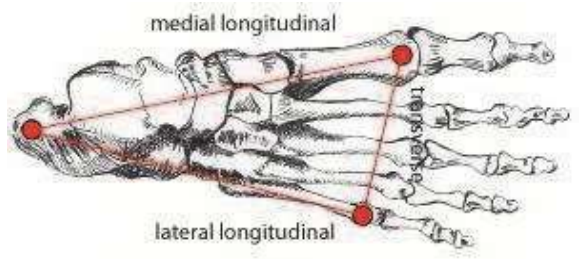

Fig. 2. The Vault of The Foot 


\section{The gait cycle}

Human stance and activity is comprised of many patterns or cycles in order to maintain us erect and move us in all directions as we live our lives. Movement can be forward, backward, side-to-side or it may rock, sway or move us up or down. Each of these movements has a totally different Activity Cycle that makes different demands upon the body biomechanically. The Walking Cycle (moving forward) and The Backward Walking Cycle challenge the bones, muscles, tendons and ligaments very differently. The fact that we have so many different biomechanical tasks to accomplish combined with the variations in stress that each of them has on the structures performing them makes it impossible to present biomechanics in an understandable manner to inexperienced minds unless we focus on one specific Activity Cycle.

Historically, in order to understand biomechanics foundationally, educators, researchers and practitioners have universally chosen The Activity Cycle of Forward Movement (walking) as the cycle to use when demonstrating, researching and monitoring FLEB. This cycle is known as "The Gait Cycle". ${ }^{24}$ It is important to note that there are variations in The Gait Cycle that include Midstance Contact Gait and Forefoot Contact Gait that impact the foot and posture differently than The Heel Contact Gait Cycle.

The Gait Cycle defines a complete step from heel contact to heel contact using one limb, either left or right. The gait cycle is first divided into a Stance Phase $(60 \%)$, when the foot is in contact with the ground, and a Swing Phase $(40 \%)$, when the foot is free floating. The stance phase is further divided into a contact phase $(10 \%)$, a midstance phase $(40 \%)$ and a propulsive phase $(10 \%)$ (See Figure 3). Since pathology develops most when the foot is touching the ground, FLEB concentrates on the stance phase of gait.

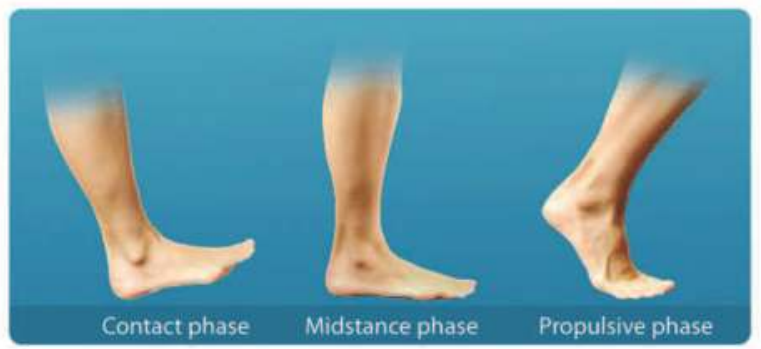

Fig. 3. The Stance Phase of Gait

Because the tendo Achilles is medially inserted on the calcaneus, it places the foot in an inverted position when the stance phase of gait begins and so the heel strikes the ground on the lateral side of the vault. As foot function cascades forward, the heel everts (pronates) in order to place the medial surface of the foot upon the ground. Because of pronation, the ball of the foot contacts the ground (midstance) with the metatarsals hitting in order of 5,4,3,2 and finally 1 as the medial side of the vault begins to support weight. Then, as the leg moves forward over the planted foot, the heel comes off the ground (Heel Rise) and when muscular power leverages to the point where they are stronger than the ground reactive forces and the metatarsal heads are firmly planted, the foot pushes off the ground (Propulsion) beginning the Float Phase of Gait. That is then repeated as we move from point A to point B. 
The supporting structure of the lateral side of The Vault of The Foot, composed of bones that when healthy, has an architecture that allows it to lock when weighted without the need for much muscular and ligamentous support. This enables the lateral Vault to be primarily strong, stable, supportive and capable of assuming an Optimal Functional Position (OFP) without much ligamentous and muscular primary or compensatory assistance in both the rearfoot and the forefoot that is different for all individuals. When the lateral column functions from Optimal Functional Position, there is little compensatory tissue stress of the bones and supporting structures or compensatory muscle engine energy on both a microscopic or macroscopic level.

In opposition, the bony architecture of the medial side of The Vault of The Foot lacks the ability to lock on its own when weighted without the assistance of a large number of primary muscle engines and ligamentous systems. This means that without strong and trained muscle engines and a well developed and conditioned ligamentous supporting system, the medial Vault of the Foot is not capable of maintaining its Optimal Functional Position and so it serves as the anatomical location for much of the biomechanical pathology that exists in both the rearfoot and forefoot (figures 4) for most feet. Collapse of the bony position of the medial side of the foot from its OFP results in stretching and reduced leverage of the ligaments and muscles that are mandated to lock and support the vault in OFP (figure 5). This creates a subclinical vicious closed chain biomechanical cycle early on that stresses the tissues on a cellular level that when repeated over and over as we live our lives eventually rises to clinical events like pain and overuse syndromes, foot and postural deformities and irreversible degenerative changes. Summarily, inherited medial vault weakness serves as the biomechanical etiology for FLEB and unless diagnosed and treated, guarantees compensatory degeneration, overuse, deformity and structural and functional breakdown in the feet and throughout the posture, in closed chain.

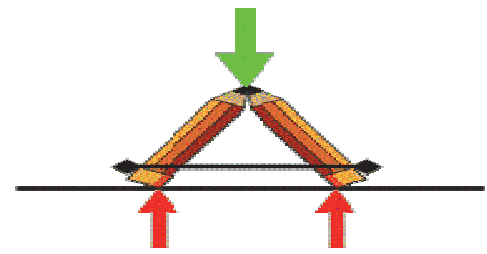

Fig. 4. The Ligamentous Tie Beam Supports The Bony Truss in the Medial Column

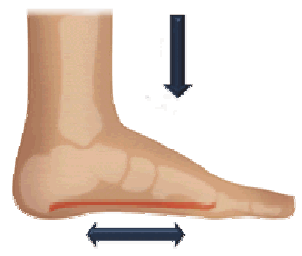

Fig. 5. The Longitudinal and Vertical Collapse of The Medial Column Deforming the OFP

The current gold standard, known as Subtalar Joint (STJ) Neutral Examination was developed thirty years ago by Podiatrist Merton Root et al. ${ }^{25}$ In this system, all feet are cast for orthotics in subtalar joint neutral position to develop orthotic shells which are then 
modified using Orthotic Reactive Postings and Modifications such as suggested by McPoil and Hunt 27 in order to reduce tissue stress in areas of complaint. Rootian Biomechanics evolved what was known as orthopedics and the prescribing of custom arch supports in the colleges of podiatry into the current biomechanics and custom foot orthotics in the 1970's. Low level research proving that STJ Neutral casted shells and prescription orders for rearfoot and forefoot corrections when ordering custom foot orthotics were beneficial are difficult to deny ${ }^{14-18}$. Unfortunately, Rootian Biomechanics is being shown to lack scientific merit and a lack of reproducibility and evidentiary proof. ${ }^{28-30}$ This may be because research is showing that in reality, most of the problems facing us in daily life involve lengthening, widening and collapse of the fore part of the foot on the sagittal and transverse planes and not the subtalar joint as Root and his followers preach. ${ }^{30-33}$

In response to this fact, modern theories are surfacing that when practiced by a new wave of biomechanically committed podiatrists are returning the podiatrist to the top of a Biomechanical Pyramid and exposing the claims of others to be exaggerated.

The doctor-patient relationship that only exists between a podiatrist using modern biomechanics to diagnose and treat the diabetic foot biomechanically using custom casting and prescribing techniques as well as individually tailored "Boot Camp" type training of the patient expands care beyond the "get sick and come to me" model of Kirby and Scherer ${ }^{34}$ and Fuller ${ }^{35}$ into more of a wellness model offered by Dananbergi1, Glaser ${ }^{33}$ and Shavelson ${ }^{38}$ that includes prevention, intervention and quality of life expansion as part of care using varied casting techniques and treatment for underlying pathology that includes prevention, intervention and quality of life expansion as part of care using varied casting prescribing and training techniques, not just complaints. One such theory gaining in popularity is called The Foot Centering Theory of Biomechanics or Wellness Biomechanics invented and U.S. Patented by this author $38-42$

\section{The foot centering theory of biomechanics}

When it comes to understanding the foot as a supportive structure, in The Foot Centering Theory of Biomechanics, the dynamic arches of the foot and The Vault of the Foot are compared to architectural arches and vaults applying the principles and terminology of architectural engineering to the positional structure of the foot (figure 6). The use of architectural language reduces the previous difficult language of physics and mechanical engineering that has distanced practitioners, patients and the foot suffering public investigating and applying biomechanics.

The architectural arches as structures have one function and that is to support. They are symmetrical (no back or front). Their pillars are equal in size, their component bricks are equal or proportional in size and shape and their keystones are centered. They resist wear and tear but fail as adaptive, functional and shock absorbing entities because they cannot provide leverage to ropes and pulleys trying to move it when attached. In opposition, pedal arches are assymetrical (they have a back and front). Their pillars are disproportional, their bones are of different size and shape and their keystones are off-centered. This means that pedal arches and vaults, in order to succeed as an adaptive, shock absorbing and mobile entities, are destined to fail as supporters (figure 6).

In Foot Centering, rather than treat all feet from a Subtalar Joint Neutral platform, feet are profiled into subgroups or types that share common characteristics called Functional Foot 
Types or FFT's. These shared structural, functional and compensatory tendencies for those that test a particular foot type provide a platform from which to provide improved custom care for every patient. Within each subgroup, each subject shares similarities with respect to weightbearing position, segmental ranges of motion, predictable areas of strengths and weaknesses and certain precursor signs and symptoms that can help predict past, present and future foot and postural breakdown and performance issues.

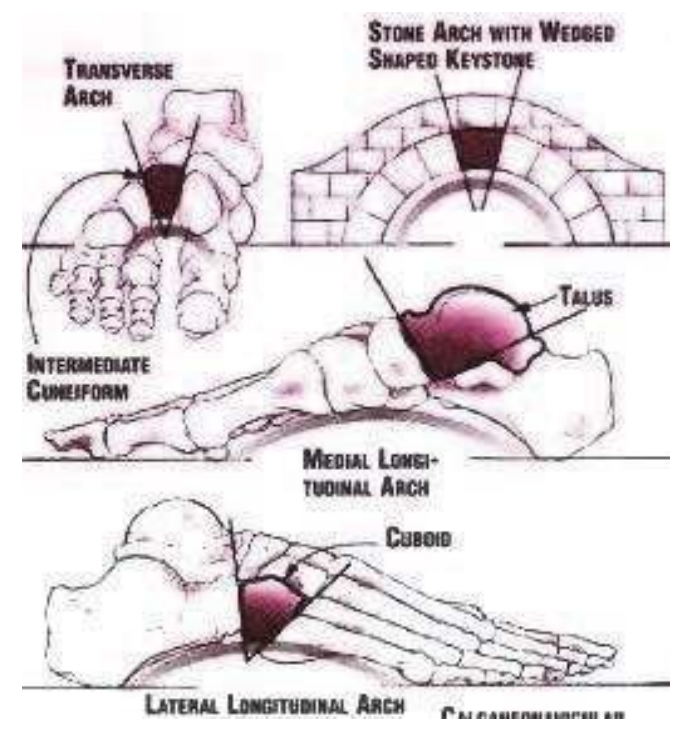

Fig. 6. Architectural vs. Pedal Arches

Starting from Root's well defined position of pedal neutrality (Figure 7) ${ }^{43}$, two simple open chain tests are performed for the rearfoot and two tests for the forefoot determine

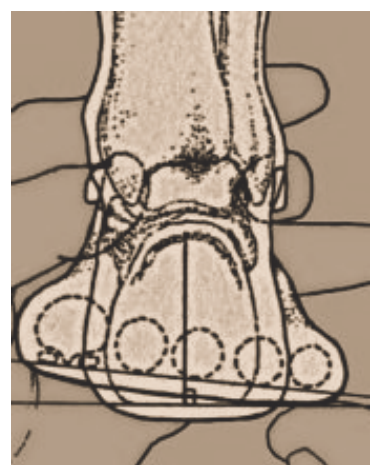

Fig. 7. Root's Neutral Position.

the Supinatory End Range of Motion (SERM) and Pronatory End Range of Motion (PERM) of each segment defining a rearfoot type and forefoot type for every foot. These two segmental foot types then combine to produce a Functional Foot Type (FFT) that serves as a 
starting platform to develop a plan of biomechanical care in the hands of a skilled professional. 37

\section{The functional foot typing system}

In The Functional Foot Typing system, the total range of motion and the positional relationships within the rearfoot (the subtalar joint) and the forefoot (the midtarsal joint) gathered in open chain can be used to describe specific foot types and how they will compensate when placed in closed chain against the ground.

The RF SERM Test represents subtalar joint position in the contact phase of The Gait Cycle and the RF PERM Test represents subtalar joint position in the midstance phase of gait. The FF SERM Test represents the first ray position at the midstance phase of The Gait Cycle and the FF PERM Test represents the first ray at the heel lift phase of propulsion (figure 8).

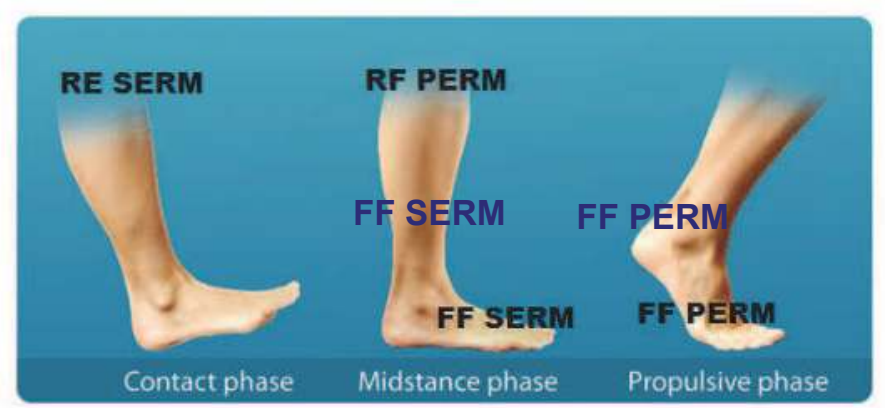

Fig. 8. The SERM-PERM Positions in Gait

The Rearfoot SERM-PERM and the Forefoot SERM-PERM tests each have four possible types that are designated Rigid, Stable, Flexible and Flat.

In trying to present functional foot typing in three paragraphs, we will begin by defining the four possible functional rearfoot types and four functional forefoot types.

\section{The rearfoot foot types}

In the rigid rearfoot type, the rearfoot total range of motion is less than 15 degrees with the calcaneus inverted to the lower leg at both SERM and PERM.

In the stable rearfoot type, the rearfoot total range of motion is 15 degrees with the calcaneus inverted to the lower leg at SERM and perpendicular to the lower leg at PERM.

In the flexible rearfoot type, the rearfoot total range of motion is greater than 15 degrees with the calcaneus inverted to the lower leg at SERM and everted to the lower leg at PERM.

In the flat rearfoot type, the rearfoot total range of motion is greater than 15 degrees in both SERM and PERM.

\section{The forefoot foot types}

In the rigid forefoot type, both the SERM and PERM position of $1^{\text {st }}$ met horizontal bisection is plantarflexed to the $5^{\text {th }}$ met horizontal bisection. 
In the stable forefoot type, the SERM position of the $1^{\text {st }}$ met horizontal bisection plantarflexed to the $5^{\text {th }}$ met horizontal bisection and the PERM position of the $1^{\text {st }}$ met horizontal bisection is online with the $5^{\text {th }}$ met horizontal bisection.

In the flexible forefoot type, the SERM position of the $1^{\text {st }}$ met horizontal bisection is plantarflexed to the fifth metatarsal head horizontal bisection and the PERM position of the $1^{\text {st }}$ met horizontal bisection is dorsiflexed to the $5^{\text {th }}$ met horizontal bisection.

In the flat forefoot type, both the SERM and PERM position of the $1^{\text {st }}$ met horizontal bisection is dorsiflexed to the fifth met horizontal bisection.

Every pair of feet can be profiled as a specific rearfoot type and forefoot type. After a subject has been diagnosed with a Functional Rearfoot Type and a Functional Forefoot Type the Functional Foot Type is determined by combining both entities. The Functional Foot Typing System allows every foot to be classified into one of sixteen possible FFT's.

\begin{tabular}{|c|c|c|c|c|c|}
\hline & \multicolumn{5}{|c|}{ Functional Forefoot Type } \\
\hline \multirow{5}{*}{ 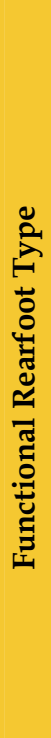 } & & Rigid & Stable & Flexible & Flat \\
\hline & Rigid & $\begin{array}{l}\text { Rigid/Rigid } \\
\text { (cavus) }\end{array}$ & Rigid/Stable & $\begin{array}{c}\text { Rigid/Flex } \\
\text { (bunion) }\end{array}$ & Rigid/Flat \\
\hline & Stable & Stable/Rigid & $\begin{array}{c}\text { Stable/Stable } \\
\text { (normal) }\end{array}$ & Stable/Flex & Stable/Flat \\
\hline & Flexible & Flex/Rigid & Flex/Stable & $\begin{array}{l}\text { Flex/Flex } \\
\text { (pronated) }\end{array}$ & Flex/Flat \\
\hline & Flat & Flat/Rigid & Flat/Stable & Flat/Flex & $\begin{array}{c}\text { Flat/Flat } \\
\text { (flat) }\end{array}$ \\
\hline
\end{tabular}

Fig. 9. The Functional Foot Typing Matrix

When the four functional rearfoot types are plotted horizontally and the four functional forefoot types are plotted vertically, a matrix composed of sixteen boxes is created, each box representing a possible functional foot type (figure 7). This means that there are 16 possible FFT's, however for the purposes of this chapter, $90 \%$ of all feet classify into one of five Common Foot Types (see figure 9)

After diagnosing a subject's foot type, a podiatrist can fabricate a positional prop in the form of a foot orthotic casted in the Optimal Functional Position (OFP) replacing his/her existing footbeds, foot type-specific. This reduces the need for the muscles to overcome 
pathological collapse allowing them to concentrate on balance and movement. Stress risers within the foot are reduced or eliminated due to healthy redistribution of weight, preventing biomechanical sequelae and preparing each patient to be trained for a better performance, efficiency and quality of life. The goal for success is strong feet and posture that performs efficiently with an end goal of reducing or eliminating the prop orthotic.

This means that by knowing the foot type of a diabetic, the location of future ulcerations and infections can be predicted and prevented utilizing biomechanical treatment to balance and distribute weight, pressure and shear away from areas these predictable areas while expanding the functional quality of life so important to the longevity and fitness of the patient.

\section{The common functional foot types}

As stated previously, we are going to focus on The Five Common Functional Foot Types that $90 \%$ of all feet profile into (Figure 10) and the forefoot biomechanics that leads to most of the biomechanical pathology seen in practice, including many ulcers and wounds that develop in the feet of diabetics.

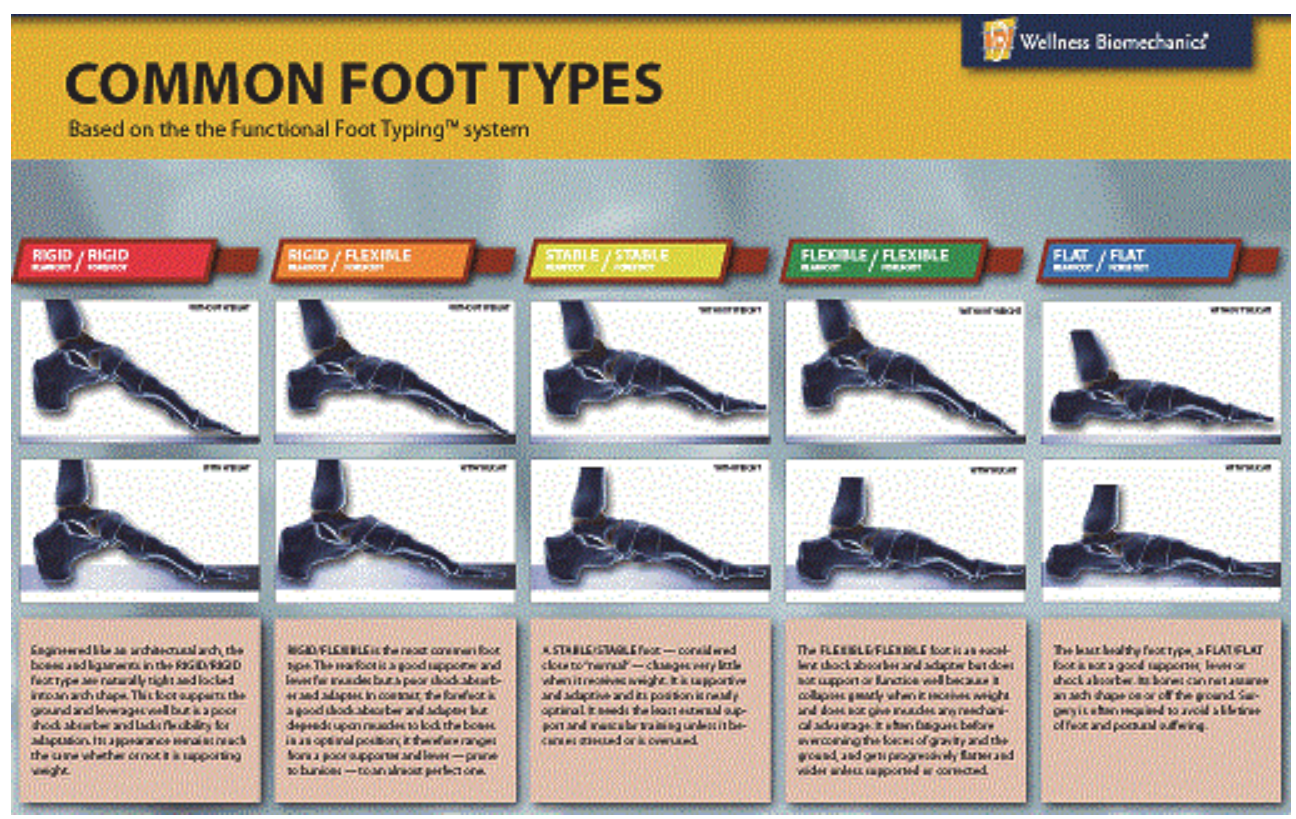

Fig. 10. The Common Functional Foot Types

The goals for success in Foot Centering are strong feet and posture that perform efficiently with reduced deformity, degeneration and suffering. In the case of the diabetic patient, we add the prevention, improved healing, reduction of invasive procedure needed and improved functional life when dealing with closed chain ulcers, wounds and infections. 


\section{The characteristics of the Functional Foot Types (FFT's) ${ }^{44}$}

Each FFT is associated with a certain profile of features that as a whole unite the members of that FFT. These include lesion pattern, x-ray presentation, shoe wear pattern, foot deformities, foot pain and postural pain and fatigue symptoms.

This means that if given the characteristics of a given patient, a biomechanically practiced podiatrist can place that patient into one of the FFT's.

Since some foot type characteristics are shared by more than one type, some patients may resemble each other and not be in the same FFT but when profiled, the foot type can be confirmed by its overall characteristics. For example, the presence of a range of motion of the $1^{\text {st }}$ ray to fifth of lets say, 35 degrees in a patient diagnosed as a rigid forefoot type probably reflects poor typing since that would definitely place that subject into the flexible forefoot subgroup.

Since they are foot type specific, pathological foot type characteristics, even if not yet evident for a given patient can be reduced or prevented by introducing OFP and compensatory threshold training as part of care.

As an example, please review the characteristics of The Rigid Rearfoot/Rigid Forefoot FFT (figure 11).

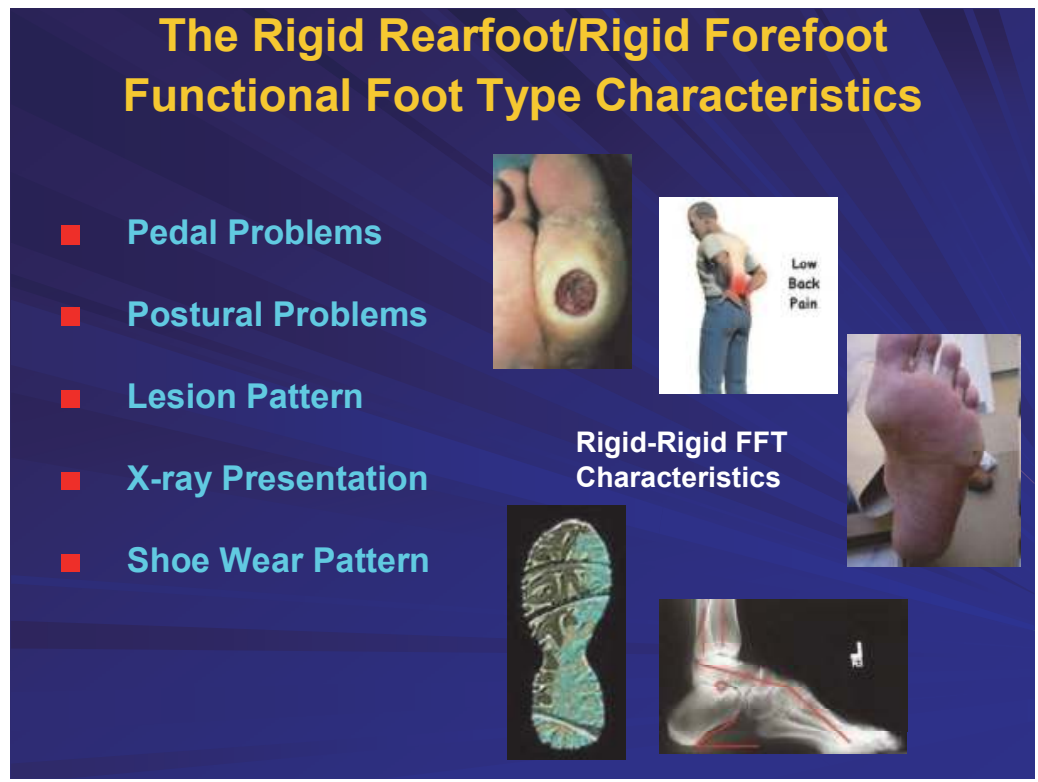

Fig. 11. The Rigid Rearfoot/Rigid Forefoot FFT Characteristics

\section{Protective callus formation ${ }^{1,39}$}

In closed chain, when an area of the foot is overloaded with weight, shear or torque, there are two possible reactive occurrences in the skin. 
The first results from an overwhelming acute force that gives the skin no time to protect itself from injury. This acute injury is known as blistering. The skin separates into two layers, a base and a roof that then fills up with body fluid or blood depending on which organs are involved.

The second event occurs when there is subclinical repetitive microtrauma in the form of shear, pressure or torque to a weightbearing area of the foot and this results in reactive compression and thickening of the epidermal layers in that area presenting itself as a cascade of changes that occur ranging from protective callus (figure 12) to ulceration and wounding (figure 13). The level of change depends on how strong and how long the microtrauma continues.

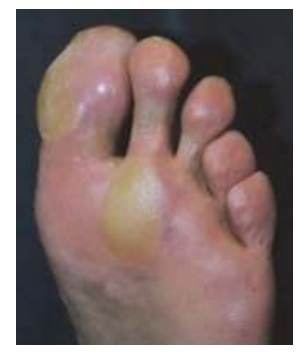

Fig. 12. Protective Callus

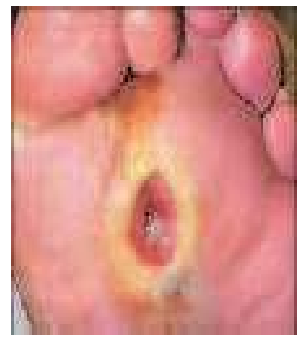

Fig. 13. Pressure Ulcer with Deep Wound

This means that if protective callus develops Functional Foot Type-Specific due at least in part to underlying, inherited biomechanical pathology, then foot typing diabetic patients, monitoring their protective calluses and treating them biomechanically utilizing Foot Centering so that they don't advance into ulcers and wounds defines the important role of The Podiatrist as an integral part of the health care team of every diabetic.

\section{Ulcer, wound and amputation prevention in diabetics utilizing foot typing}

The application of Functional Foot Typing that best serves the diabetic is to look at the functional forefoot type and state the location of forefoot callus for each of the Common Foot Types. Whether these calluses exist or not on a patients biomechanical timeline, these areas are accepting greater than normal tissue stress which will cascade to ulceration unimpeded in the face of diabetic neuropathy and must be decompensated biomechanically. ${ }^{45-49}$ 


\section{The common functional foot type/ callus-ulcer patterns}

Figure 14 introduces the reader to the predictable sites of excess closed chain weight forming callus. Although the body's desire is to protect these areas from injury, like the fingertips of a guitar player, continued ground and shoe reactive forces cascades the clinical picture to that of the very injury it is attempting to prevent .

After diagnosing a subject's foot type, a podiatrist can fabricate a positional prop in the form of a foot orthotic casted in the Optimal Functional Position (OFP) for that type. This reduces the need for the muscles to overcome pathological collapse allowing them to concentrate on balance and movement. Stress risers within the foot are reduced or eliminated preventing biomechanical sequelae and preparing each patient to be trained for a better foundational positioning and muscle engine performance. In addition, the need for protective callus formation reduces or is eliminated ${ }^{42}$.

\begin{tabular}{|l|r|}
\hline Functional Foot Type & First Met Callus, 5 \\
\hline Rigid/Rigid FFT & \\
\hline Rigid/Flexible FFT & Callus Hallux IP Joint, 2nd Met If Stressed, No Ulcer \\
\hline or Wound Formation
\end{tabular}

Fig. 14. Callus-Ulcer patterns of the Common FFT's

\section{Why is the diabetic foot so prone to problems?}

All of us inherits a functional foot type and are prone to accept its strengths and weaknesses. This inevitably leads us to suffer predictable quality of life issues due to biomechanical wear and tear and inefficient compensatory mechanisms that are impacted by concomitant factors such as weight, body type, age, activity level, health state, ground surfaces, equipment and vocation. 
However, no one factor is so overwhelmingly important to consider when rating the importance of podiatry care in the form of functional lower extremity biomechanics than Diabetes Mellitus. This is because diabetics inheriting these very same FFT's end up with greater quality of life issues including ulcerations, infections, deformities and amputations than their non diabetic counterparts due to the devastating comorbidities of peripheral neuropathy and PAD. The most devastating component comorbidity of DM relates to the fact that neuropathic diabetics lose what is known as proprioception or the ability to "feel and react to the road and navigate through it".

Walking and many other tasks require daily closed chain sensory input to adapt and modify motor patterns and muscle output to carry out the desired task. Fully functioning joints and bones, combined with adequate muscle strength, are needed. The result of this activity is also coupled with local soft tissue compensations affecting the foot-ground interface. These can be affected by the frictional properties of the sole, internal muscle activity as well as the inherited underlying biomechanics of each subject that can be improved with foot orthotics. ${ }^{50}$

\section{Proprioception}

Proprioception is defined as "sensing the motion and position of the body. Knowing where we are in space and judging how we should navigate that space is a biological quality that when combined with our intelligence, elevates us from the rest of the animal kingdom.

Specialized nerve endings called Proprioceptors are present throughout the soft tissues of the musculoskeletal system. They interact with the central nervous system and coordinate our body movements, our postural alignment, and our balance. We rely on this delicately controlled and finely-tuned system of receptors and feedback loops and the validity and reliability of the information which is sent into the spinal cord tens of thousands of times every day.

Proprioceptive health allows us to "read" our environment in order to generate appropriate motor responses to perform the motions, actions, tasks and functional skills that we must perform. A reduction of Proprioception impacts our ability to stand weighted without sway as well as our ability to perform artistic and athletic physical activity efficiently and to move from point " $\mathrm{A}$ " to point " $\mathrm{B}$ ".

Over time, areas of the body without adequate proprioception are exposed to increased tissue stress that weaken, deform, degenerate and eventually break down the skin, connective and supportive soft tissue, ligaments, tendons, muscles, bones and joints in those areas as well as in other areas of the body that must compensate secondarily in order keep the body performing.

The current scientific literature supports the following changes in the diabetic foot as a result of peripheral neuropathy: limited joint range of motion, glycosylation of tendons and soft tissue leading to restriction of motion, diminished plantar fat padding, and intrinsic muscle wasting with resultant clawing deformity of toes and contractures of the forefoot. ${ }^{45-51}$

Although it cannot be stated with certainty in all cases, there is evidence to state that underlying biomechanical pathology results in reductions in joint range of motion (functional hallux limitus, functional hallux extensus and ankle equinus to name a few) in 
the lower extremity. This results in stress in ligaments and tendons and joints such as the tendo Achilles, plantar fascia and great toe joint, especially in those foot types that are hypermobile such as the rearfoot and forefoot stable and flexible types. This in turn produces enlargement and fibrosis as well as subsequent contractures and weakness in the foot due to the sum of the repetitive micro injuries to the soft tissues, ligaments, muscles, tendons, joints and bones. ${ }^{52-55}$

Examples of where functional foot typing predicts locations for wounds, infections and ulcers would be the $2^{\text {nd }}$ toe hammertoe prevalent in the rigid rearfoot-flexible forefoot FFT, The fifth met head lesions and wounds of the flat rearfoot-flat forefoot foot type, the hallux IP Rolloff Ulcers that cause hallux amputations are allied to the flexible rearfoot-flexible forefoot functional foot type and the severe ulceration of the plantar $1^{\text {st }}$ metatarsal head that often leads to osteomyelitis of that area is linked to the rigid rearfoot-rigid forefoot FFT.

In diabetes, Loss of Protective Sensation (LOPS), the end stage of proprioceptor pathology, by eliminating the pain protection response from the equation, leads to overwhelming integumentary tissue stress that is not decompensated due to the fact that the body cannot recognize its existence. This leads to pressure callus, pressure ulcers and wounds, amputations and limb loss because of a lack of proprioceptive warning. Proprioceptive pathology is an early and common finding in the polyneuropathy peripheral neuropathy associated with the disease and may even precede the presence of high fasting blood sugars (prediabetics).

Summarily, insufficient information supplied by Proprioceptive Sensors reduces efficiency of movement, causes pathologic tissue stress, injury, problems with postural coordination and/or joint alignment and chronic, un-resolving pain in sensate areas as well as skin and soft tissue wounds and ulcers in advanced cases.

\section{Locations of nerve receptors}

The most important sensory nerve organs for controlling the muscular system are the muscle spindle fibers and the Golgi tendon organs.

Muscle spindle fibers are found interspersed within the contractile fibers of all skeletal muscles, with the highest concentration in the central portion (belly) of each muscle. Muscle spindles respond to changes in muscle length and stress. Without this basic "wiring," proper joint alignment can't be maintained and closed chain stance is almost impossible. ${ }^{58-59}$

Golgi tendon organs are located in the junctions of muscles and their tendons. These protective nerve endings exert an inhibitory effect on contraction of muscle fibers (figure 15).

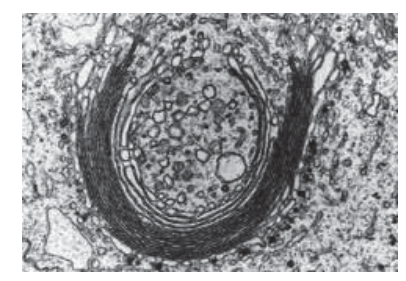

Fig. 15. A Golgi Tendon Organ 


\section{Joint mechanoreceptors (Table 2)}

Surrounding and protecting all joints are tough, fibrous tissues that contain a variety of sensory nerve endings. The input from these specialized sensors keeps the nervous system informed as to the location of the joint, and also their degree of stress they are under by monitoring stretch, compression, tension, acceleration, and rotation.

Type I mechanoreceptors are found in higher densities in the proximal joints. They sense the position of a joint by signaling the joint angle through normal ranges of motion. These help determine postural (tonic) muscle contractions.

Type II nerve endings adapt to changes in position, and are most active at onset and termination of movement. These are more densely distributed though the distal joints, and affect phasic muscle actions.

Type III mechanoreceptors are high-threshold, which means they require considerable joint stress at end ranges before firing. These receptors serve a protective function similar to the Golgi tendon organs.

Type IV receptors are free nerve endings located in the ligaments, joint capsules, and articular fat pads which respond to pain stimulus. They can generate intense, non-adapting motor responses in all muscles related to a joint, resulting in the protective muscle contractions that restrict joint movement.

\begin{tabular}{|c|c|}
\hline muscles and tendons & $\begin{array}{c}\text { muscle spindle fibers } \\
\text { Golgi tendon organs }\end{array}$ \\
\hline $\begin{array}{c}\text { joint ligaments and capsules } \\
\text { (mechanoreceptors) }\end{array}$ & $\begin{array}{c}\text { type I - low threshold, slow-adapting } \\
\text { type II - low threshold, fast-adapting } \\
\text { type III - high threshold, slow-adapting } \\
\text { type IV - nociceptive (pain endings) }\end{array}$ \\
\hline
\end{tabular}

Table 2. Sensory Organs for Proprioception

In addition, stretch-sensitive receptors in the skin known as Ruffini ending, the Merkel cells in hairy skin and field receptors also signal postural and sensory information.

\section{The biomechanics of proprioception in the diabetic foot}

There are over 200 additions to the literature showing that custom orthotic support can help improve structural alignment, balance, gait, and athletic performance. ${ }^{66-69}$ In addition, therapeutic shoes and orthotics have been shown to be effective in treating and preventing wound and ulcer formation and they are approved by U.S. Medicare for annual dispensing to diabetics as a cost saving to the health care budget. ${ }^{70}$

It has been suggested that this universe of improvements is due primarily to upgrades in the sense of proprioception. ${ }^{66}$ A quick review of the mechanisms and components of proprioception will help us comprehend how patients can demonstrate such a large variety of improvements. Being able to explain this to patients (using simpler terms, of course) will 
help them understand the reasons you are recommending they wear in-shoe orthotics and train their muscle-tendon units to a higher fitness level.

Except for the spine, the foot is the anatomical region that contains the most proprioceptive sensory receptors. Because of the magnitude of sensory input, the feet are quick to produce problems when denied proprioception. These are magnified by the fact that the foot must additionally deal with ground reactive forces and hard, unyielding shoe boxes. Loss of balance, missteps, falls and a reduced ability to navigate efficiently and accurately are just some of the sequelae accompanying proprioceptive disease. Underlying foot type-specific biomechanical pathology impacts pedal posture, pedal muscle engine efficiency and the ability to perform tasks such as walking, lifting and recreational activities and when they exist in a diabetic, cause escalation of its musculoskeletal comorbidities.

\section{Pedal involvement}

The six specialized nerve sensors are found throughout the musculoskeletal system, in all skeletal muscles and in every ligament, joint capsule, and articular connective tissue. However, the feet are particularly well-supplied with proprioceptive nerve endings. Mechanoreceptors in the joints, along with the muscle spindles of the foot muscles are responsible for the positive support reflexes and a variety of automatic reflexive reactions ${ }^{71}$. These include the flexor/extensor reflex, which converts the lower limb into a firm, yet compliant pillar. Weightbearing compresses the joints and muscles, evoking reflexive activity in the extensors and inhibition of the flexor muscles.

\section{The vicious cycle of proprioceptive loss and peripheral neuropathy}

Second only to glucose control when it comes to managing diabetes is the need to be active and exercise. Increased metabolic disease via peripheral neuropathy causes a reduction in sensory perception of soft touch, pinprick, vibration, and pain eliminating a diabetic from recognizing and reacting to them. Proprioceptive deficits, on the other hand reduce a diabetics ability to know where they are, where they are going and how they are positioned in closed chain. It is the reduced proprioception causes diabetics to live their lives at a slower pace and reduced activity. This in turn allows the metabolic disease to become progressively worse causing advancement of the peripheral neuropathy. ${ }^{72}$

It is the job of the health care team to foster diabetics to increase their activity levels efficiently for the long term. In a foundational sense, this begins with pedal support, improved proprioception, healthy compensation of underlying biomechanical pathology and the incorporation of monitored training and exercise programs into the lives of all diabetics. Until this is accomplished, diabetes will continue to fester in greater portion when compared to the rest of the population and the economic and social drain that diabetes places on society will continue to mount ${ }^{73}$.

Like other paradigms of functional lower extremity biomechanics and foot orthotic use, there is little high level evidence available for practitioners to apply in using foot typing as a starting platform. OFP casting and Foot Type-specific prescribing anecdotally allow for more organized and predictable diagnosis and treatment of underlying biomechanical pathology. By preventing postural collapse and reducing the need for primary muscle engines to participate in postural alignment and efficiency, they foster all other aspects of 
lifestyle upgrading and therefore it should be considered in the care of diabetics that suffer from underlying biomechanical pathology in the face of the dilution that has occurred for the current Rootian standard.

\section{The biomechanics of Charcot Joint Disease}

To site an example of the application of functional foot typing and Foot Centering Biomechanics to the ever-present factors in the development and progression of the comorbidities of diabetes and how podiatric closed chain diagnosis and treatment of these entities needs to be a part of the health care team one needs only to inspect Charcot Joint Disease (CJD).

\section{Charcot Joint Disease (CJD)}

Any physician treating patients with diabetes is aware that on any visit a patient can present with a foot or ankle that is red, hot, and swollen that is not infected. This presentation signals the beginning of a destructive process affecting the soft tissues and bone structure of the foot and ankle called Charcot Joint Disease (CJD). It leads to joint and osseous collapse and degeneration, functional disability, ulceration, infection and eventual loss of limb. Understanding the etiology and progression of this process should be one of the goals of all members of the diabetes health care team, especially those involved in primary care.

Although there is significant literature related to the diagnosis and treatment of Charcot joint once it develops ${ }^{74,76}$, there has been little discussion as to the predisposing Biomechanical Risk Factors that precede the development of Charcot foot and the need for preventive biomechanical treatment once it exists.

The Precursors of Charcot Joint Disease (CJD) The pathophysiology of Charcot joint disease (CJD) remains unknown. One prevalent theory (Volkmann and Virchow) is named the neurotraumatic theory. ${ }^{77}$ This theory proposes that the joint destruction of CJD is due to a neuropathic foot that leads to loss of proprioception and pain sensation, thereby permitting joints to be exerted to the point of collapse and destruction.78 The neurotraumatic theory finds support in studies which demonstrate that plantar pressures are higher in the metatarsophalangeal joints of the forefoot in patients with acute CJD compared to patients with distal sensorimotor neuropathy or neuropathic ulceration. ${ }^{75}$ In addition, the motor neuropathy in the diabetic lower extremity tends to precipitate a weakness of muscle groups in the lower extremity, creating dynamic and functional imbalances that either initiate or compound deformities within the foot.

Whether there is feeling the foot or not, the level of underlying biomechanical pathology that exists will determine the level and rate of progression of the cascade of degeneration, deformity, disuse and injury that an individual suffers.

We all suffer from subclinical injury that is of a biomechanical nature. Cellular and tissue stress that goes beyond physiological tolerance. These injuries repair and may even stimulate the development of stronger and more capable cells and tissues. However, once these stresses pass certain thresholds, clinical injury occurs accompanied by various signs and symptoms. These signs and symptoms alert one to address the injury so as to keep it from progressing. Pain, heat, pressure and pinching present early in injury and send a message to change ones lifestyle, environment or metabolism in order to prevent an injury 
from worsening. In the advanced stages of peripheral neuropathy, there is an absence of these cellular and tissue alarms allowing injuries to progress to a much higher level before becoming clinically evident. This phenomenon is known as Loss of Protective Sensation or LOPS.

This phenomenon, when present in a diabetic that has inherent underlying biomechanical pathology, instead of presenting with painful bunions, stress injuries or ligamentous stresses such as plantar fasciitis, presents with a pathological collapse of the foot, involving insensate joints that have lost proprioception in their end nerve organs that is The Charcot Foot.

In the Functional Foot Typing System, it is the stable and flexible rearfoot and forefoot foot types that are most commonly involved in Charcot Foot. The rigid and flat rearfoot and forefoot foot types, on the other hand resist collapse and the type of injury that may be a precursor of CJD.

More specifically, advanced flexible rearfoot types tend to lead to ankle CJD while moderate ones tend more towards a medial collapse under the navicular that leads to cuboidal ulcers and wounds. In contrast, the flexible forefoot foot types lead to $1^{\text {st }} \mathrm{MP}$ Joint neuroarthropathy and transfer ulceration under the $2^{\text {nd }}$ metatarsal head, the IP Hallux and sub $5^{\text {th }}$ metatarsal head. ${ }^{94}$

\section{The pre-charcot foot ${ }^{80}$}

When discussing the Charcot foot, the literature consistently points to the existence of peripheral neuropathy and a loss of protective sensation as necessary in order to develop a Charcot Foot and the presence of patent, healthy circulation in order for the hyperemia of CJD to occur. If ischemia is present, wet or dry gangrene, rather than CJD develops.

Finally, whether primary or secondary, trauma or repetitive micro-trauma is necessary in order for CJD to progress. This trauma is exacerbated by closed chain factors such as obesity and an active lifestyle that must be appreciated and overcome by the examiner in order to treat CJD successfully.

In summary we have defined the pre-Charcot foot as a clinical entity displaying the following quartet of signs and symptoms:

1. Loss of Protective Sensation (LOPS)

2. Patent Circulation

3. Underlying Pedal Biomechanical Pathology and Weakness (Functional Foot Typing)

4. Excessive Closed Chain Factors (obesity, over-activity, etc.)

Inherent pedal biomechanical pathology and weakness (see biomechanics)

The presence of inherited, underlying biomechanical pathology is almost universal in the development of CJD. It is indeed rare to find a foot with normal mechanics go on to develop CJD probably because those diabetics find it easier to navigate through lives more actively. 


\section{Excessive closed chain factors}

The lifestyle and quality of life of each individual varies in many ways when in closed chain. A careful history revealing the existence and extent of closed chain factors will assist a practitioner to determine their impact on the need to actively treat a subject's functional foot type. A person who is morbidly obese, very active and wearing worn out athletic shoes may need treatment even if he/she has a stable foot type. Conversely, in the face of LOPS, patent circulation and biomechanical pathology, a healthy and fit, light weight person, who is not very active and wear well fitted shoes and socks that are not outworn has much less of a chance to develop a Charcot Foot.

\section{Discussion}

Biomechanically, we would like individuals to have a lifestyle that includes exercise along with varied daily activities that promote aerobic health and functional fitness. Our goal should not be to reduce patients from being active and living a healthy lifestyle but instead to promote an active lifestyle for all while supporting them and training them biomechanically, injury, deformity and wound free.

Even though podiatry has become more and more an acceptable part of the diabetes health care team, there remains a poor understanding of functional lower extremity biomechanics and the need for diagnosing and treating underlying biomechanical pathology before, during and after the devastating comorbidities of diabetes reveals itself clinically. It is the hope of the author that all readers will be stimulated to increase their knowledge base regarding the needs of the diabetic patient when it comes to their feet so that foot suffering diabetics can be better cared for.

The podiatrist, skilled in closed chain medicine, biomechanical pathology and the diagnosis and treatment of the functional foot types is a necessary part of the health care team involved in treating diabetics. An annual foot exam and necessary follow-up that includes functional lower extremity biomechanics should be a mandatory part of the care of every diabetic and capable of being delivered by all members of the health care team.

\section{References}

[1] Shavelson, D, Steinberg, J, Bakotic B. The Diabetic Foot, Chapter 25, The Principles of Diabes Mellitus, 2010, 6, 381-399 2nd Printing, DOI: 10.1007/978-0-387-09841-8_25, Springer International Publishing

[2] Arad Y, Fonseca V, Peters A; Beyond the Monofilament for the Insensate Diabetic Foot: A systematic review of randomized trials to prevent the occurrence of plantar foot ulcers in patients with diabetes; Diabetes Care, April 2011. vol.34 no $4,1041-46$

[3] Southern Arizona Limb Salvage Alliance patient information. Available at: http:/ / diabetic-foot.net/CLEAR/Patients.html. Accessed August 31, 2010 
[4] Manes J, Papazoglou J, Sossidou E, Soulis, K; D. Milarakis; Prevalence of Diabetic Neuropathy and Foot Ulceration: Identification of Potential Risk Factors-A Population-Based Study; Wounds, 14(1):11-15, 2002

[5] Boulton AJ, Vileikyte L, Ragnarson-Tennvall G, Apelqvist J. The global burden of diabetic foot disease. Lancet 2005;366:1719-1724.

[6] Moxey, P, Gogalniceanu, P, Hinchliffe, R; Lower extremity amputations-a review of global variability in incidence: Diabetic Medicine, vol 28 issue 10, p 1144-53, October 2011

[7] MacKenzie EJ, Jones AS, Bosse MJ, et al. Health-care costs associated with amputation or reconstruction of a limb-threatening injury. J Bone Joint Surg Am. Aug 2007;89(8):1685-92

[8] 16(11):1507-10, 1993.Kenny SJ, Smith PJ, Goldschmid MG, Survey of physician practice behaviors related to diabetes mellitus in the U.S: Physician adherence to consensus recommendations. Diabetes C:16(11):1507-10, 1993.

[9] Andrew J, Boulton M, Kirsner, M; Neuropathic Diabetic Foot Ulcers: New Eng Jour Med; July 1, 2004, 351;48-55

[10] Payne C; The Past, Present and Future of Podiatric Biomechanics; Jour Amer Pod Med Ass;Feb 1998;88-2;53-63

[11] Shavelson, D; The Tower of Biomechanics: The Foot in Closed Chain, Present Podiatry E-zine; 06/26/2009; http:/ / www.podiatry.com/ezines/?pub_year=2009\&section_id=51\#ezine483

[12] Prior T; The practical application of biomechanical theory for patient assessment: J Foot Ankle Res, May 2011; 4 29-37

[13] Shavelson D; Current Mainstream Biomechanics: Part I The Science and Current Paradigms: The Foot in Closed Chain, present Podiatry E-zine; 08/02/10; http:/ / www.podiatry.com/ezines/?pub_year=2010\&section_id=51\#ezine723

[14] Gross MT, Byers JM, Krafft JL, Lackey EJ, Melton KM: The impact of custom semirigid foot orthotics on pain and disability for individuals with plantar fasciitis. J Ortho Sp Phys Ther, 32:149-157, 2002.

[15] Powell M, Seid M, Szer IA: Efficacy of custom foot orthotics in improving pain and functional status in children with juvenile idiopathic arthritis: A randomized trial. J Rheum, 32:943-950, 2005.

[16] Kirby KA: Conservative treatment of posterior tibial dysfunction. Podiatry Management, 19:73-82, 2000

[17] Mundermann A, Wakeling JM, Nigg BM, Humble RN, Stefanyshyn DJ: Foot orthoses affect frequency components of muscle activity in the lower extremity. Gait and Posture, In Press, 2005.

[18] Dananberg HJ, Guiliano M: Chronic low-back pain and its response to custom-made foot orthoses. Jour Amer Pod Med Ass; 89:109-117, 1999

[19] Kemp M; Artists on Science: scientists on art; Nature 434, March 17, 2005;306-09

[20] Root-Bernstein, R, Root-Bernstein M; Artistic Scientists and Scientific Artists: The Link between Polymathy and Creativity: Jour Amer Psych Ass, Nov 2004, pp. 127-151 
[21] Kelly G, Gitzgerald D; Open vs. closed chain exercise; Jour of Phys Ther, Dec 1997, 12934

[22] Singh N, Armstrong D, Lipsky B, Preventing foot ulcers in patients with diabetes: JAMA, Jan 12, 2005, vol 292 no 217-28

[23] Kapandj, I; The Physiology of the Joints, Vol 2 Lower Limb, 5th Edition, 2002, ChurchillLivingstone Publishing

[24] Inman V, Ralston H, Todd F: Human Walking. Baltimore: Williams \& Wilkins; 1981

[25] Root M, Orien W, Weed J; Clinical Biomechanics, Vol II Normal and abnormal function of the foot, Clinical Biomechanics Corporation, Los Angeles, CA, USA

[26] Kennedy S: Casting for foot orthotics... What works best? O\&P.com http://www.oandp.com/articles/2004-08_08.asp

[27] McPoil, T, Hunt, G: Evaluation and Management of Foot and Ankle Disorders: Present Problems and Future Directions. Jour Ortho \&Sports Phys Ther, Vol 21, Number 6, 1995, pp381-88

[28] Lee, W; An historical appraisal and discussion of the Root Model as a clinical system of approach in the present context of theoretical uncertainty: Clinics id Pod med \& Surg, vol 18 no 1, Oct 2001 555-684

[29] Kirby K: Are Root Biomechanics Dying? Podiatry Today, Apr 1, 2009, p126-31

[30] Payne C, Miller K: Variability of neutral position casting of the foot; Jour Amer Pod Med Ass, 93 1, 1-5, 2003

[31] Dananberg H; Saggital Plane Biomechanics: Jour Amer Pod Med Ass, vol 90 no 1, p 29298, Jan 2000

[32] Dananberg H: Gait style as an etiology to chronic postural pain: Jour Amer Pod Med Ass; vol 83 no 6, p443-41 August 1993

[33] Glaser E, Bursch D, Currie S: Theory and practice combine for custom orthoses: Biomechanics; vol 12 no 9, p111-15, Sept 2006

[34] Scherer, P, Kirby K: Recent Advances in Orthotic Therapy: Improving Clinical Outcomes with a Pathology-Specific Approach; LER Publishing, USA, 2011

[35] Fuller,E: Center of pressure and its theoretical relationship to foot pathology; JAPMA, June 1999, vol 89, no. 6, pp278-91

[36] Kuhn DR, Shibley NJ, Austin WM, Yochum TR. Radiographic evaluation of weight bearing orthotics and their effect on flexible pes planus. J Manip Physiol Ther 1999;22(4): p 221-226

[37] Albert, S, Curran S, Lower Extremity Biomechanics: Theory and Practice Vol II, 139-42 BiPedMed Publishing, Denver USA (in press)

[38] Shavelson D: A closer look at Neoteric Biomechanics; Podiatry Today; vol20 issue 9, p142-49, Sept 2007

[39] Shavelson D: Current Mainstream Podiatric Biomechanics Part II: The Foot Centering Theory; Present Podiatry E-zines; 11/05/10 http:/ / www.podiatry.com/ezines/?pub_year=2010\&section_id=51\#ezine730

[40] Shavelson D, Henry L: Aching Feet...Aching Back...Is there a connection?; Radius Magazine, p203-209, Winter 2008

[41] Shavelson D: Profiling the pedal snowflakes; Present Podiatry E-zines, 09/14/09 http:/ / www.podiatry.com/ezines/?pub_year=2009\&section_id=51\#ezine509 
[42] Shavelson, D: Foot Typing Method; U.S. Patent \# 7938788, Issue Date: May 10, 2011

[43] Burns MJ: Non-weightbeaing cast impressions for the construction of orthotic devices. JAPA, 67(11): 1977.

[44] Shavelson D: Functional Foot Type Closed Chain Characteristics; Present Podiatry Ezines, 05/05/2011, http://www.podiatry.com/ezines/\#ezine810

[45] Spink M, Menz, H, Lord S: Distribution and correlates of plantar hyperkeratotic lesions in older people; Jour Foot Ankle Research, 2:8, Feb 2009

[46] A, Sanjari,M, Haghdoost A: Common foot features of 247 Iranian patients with diabetes, International Wound Jour, Apr 21, 2009

[47] Frykberg R: Diabetic Foot Ulcers: Pathogenesis and Management; Amer Fam Physician, vol 66 no, p 1159-62, Nov 9, 2002

[48] Cavanagh P, Ulbrecht J, Caputo G. New developments in the biomechanics of the diabetic foot. Diabetes Metab Res Rev, 16:1, 2000

[49] Spencer SA. Pressure relieving interventions for preventing and treating diabetic foot ulcers. Cochrane Database of Systematic Reviews, Issue 32000

[50] Kim R, Edelman S, Kim D: Musculoskelatal complications of Diabetes :mellitus; Clinical Diabetes; 19:132-5 Aug 2001

[51] Yentes J, Perell K: Diabetic peripheral neuropathy and exercise; Jour Amer Kines Ass, p29-36, Fall 2006

[52] Zimny S, Schatz H, Pfohl M: The role of limited joint mobility in diabetic patients with an at-risk foot. Diabetes Care 27:942-946, 2004

[53] Wrobel J, Najafi B: Diabetic foot biomechanics and gait dysfunction; J Diabetes Sci Technol, 4(4), p833-45, July 1, 2010

[54] Tajaddini A, Scoffone HM, Botek G, Davis BL. Laser-induced auto-fluorescence (LIAF) as a method for assessing skin stiffness preceding diabetic ulcer formation. J Biomech. 40(4), p736-41, May 2007

[55] Bolton NR, Smith KE, Pilgram TK, Mueller MJ, Bae KT. Computed tomography to visualize and quantify the plantar aponeurosis and flexor hallucis longus tendon in the diabetic foot. Clin Biomech, 20 (5) p 540-, June 2005

[56] Sinacore DR, Bohnert KL, Hastings MK, Johnson JE. Mid foot kinetics characterize structural polymorphism in diabetic foot disease. Clin Biomech, vol 23 no 5, p 65361, Jan 2008

[57] Christensen K: Adjunctive therapies to the adjustment improving proprioceptive balance with orthotic support; Jour North Amer Rehab Spec, Autumn 2011

[58] Metz-Schimmer S: Functional anatomy and biomechanics of the ankle joint; Radiologe, vol 35 no7, p425-28, Jul 1995

[59] Novachek T: The biomechanics of running, Gait and Posture, 7, p77-95, June 1998

[60] Bakotic B. Shavelson D: The Pathogenesis of dystrophic toenails; Podiatry Management, p133-140, August 2006

[61] Fabrikant J: Plantar faciitis (fasciosis treatment outcome study: plantar fascia thickness measured by ultrasound and correlated with patient improvement; Foot vol 21 no 2, p79-83, Mar 12, 2011 
[62] Root ML, Orien WP, Weed JH. Normal and Abnormal Function of the Foot. Vol 2. Los Angeles, Calif: Clinical Biomechanics; 1977

[63] Kararizou E, Manta P, Kalfakis N, Vassilopoulos D: Morphometric study of the human muscle spindle. Anal Quant Cytol Histol, 27, p 1-4, june 2005

[64] Moore, M: Golgi Tendon Organs: Neuroscience Update with Relevance to Stretching and Proprioception in Dancers; Jour Dance Med \& Sci, vol 11 no 3, p 85-92, Sept 2007

[65] Slosberg M. Effects of altered afferent articular input on sensation, proprioception, muscle tone and sympathetic reflex responses. J Manip Physiol Ther;11:400-408, Apr 1988

[66] MacLean C, Hamill J: Short and long-term influence of a custom foot orthotic intervention on lower extremity dynamics in injured runners. Annual International Society of Biomechanics Meeting, Cleveland, September 2005

[67] Saxena A, Haddad J: The effect of foot orthoses on patellofemoral syndrome; Jour Amer Pod Med Ass, vol 93 no4.p 264-71, July 2003

[68] Rome K, Brown C: Randomized clinical trial into the impact of rigid foot orthoses on balance parameters in excessively pronated feet; Clin Rehab, vol 18, p 624-630, Nov 2004

[69] Lobmann R, Kayser R, Kasten G: Biomechanical evaluation of foot pressure and loading force during gait in rheumatoid arthritic patients with and without foot orthoses; Kurume Med J, 47, p211-217, Jan 2000

[70] Woolridge J, Bergeron J, Thornton C: Preventing diabetic foot disease: lessons from the Medicare therapeutic shoe demonstration; Amer J Public Health, vol 86 no 7, p93538, July 101996

[71] Ochsendorf D, Mattacola C, Arnold B: Effect of orthotics on postural sway after fatigue of the plantar flexors and dorsiflexors; Jour Athletic Training. Vol35 no 1, p26-30, Jan 2000

[72] Armstrong D, Lavery L, Holtz-Neiderer K, et al: Variability in activity may precede diabetic foot ulceration. Diabetes Care, vol 27 no 8, 1980-84, Aug 2004

[73] Mokdad A, Ford E, Bowman B, et al: The Continuing Increase in Diabetes in the United States; Diabetes Care; 10. 24.2, Feb 2001, pp207-11

[74] Sinacore D, Withrington N. Recognition and management of acute neuropathic (Charcot) arthropathies of the foot and ankle: J Orthop Sports Phys Ther; vol 29 no12, p736-46, Dec 1999

[75] Lamm B, Gottlieb H, Paley D. A two-stage percutaneous approach to charcot diabetic foot reconstruction: J Foot Ankle Surg vol 49 no 6, p517-22, Nov-Dec 2010

[76] Yu G, Hudson J: Evaluation and treatment of stage 0 Charcot's Neuroarthropathy of the foot and ankle; Jour Amer Pod Med Ass, vol 92, p 210-20, Feb 2002

[77] Kelly M, Kearsley R, Mitchell D: The neurogenic theory of arthritis. J Hist Med Allied Sci; vol 20, p151-57, June 1965

[78] Brower A, Allman R: Pathogenesis of the neurotrophic joint: neurotraumatic vs neurovascular; Radiology;139: 349, 1981

[79] Banks A, McGlamry E: Charcot Foot; J Am Pod Med Assoc. 79: 5, 1989 
[80] Poretsky L, Shavelson D, Kline M, Levine P: The PreCharcot Foot, A New Clinical Entity; Practical Diabetology, vol 14 no 3, p139-43, September 2006

[81] Damodar R. Ambur and James H. Starnes, Jr., NASA Langley Research Center, Hampton, VA: Presented at the 39th AIAA/ASME/ASCEIAHS/ASC Structures, Structural Dynamics, and Materials Conference, Long Beach, California April 20-23, 1998

[82] Liu D, Schultz P: Dynamic failure and energy absorption of composites with topological control; $16^{\text {th }}$ international conference on composite materials, Michgan State University, 2007

[83] Jobjes M, Heuschel G, Pretzel C: Repetitive training of compensatory steps: a therapeutic approach for postural instability in Parkinson's Disease; J. Neurol. Neurosurg Psychiatry, 75, 1682-87, 2004

[84] Shavelson D: The Future of Biomechanics; Present Podiatry E-zines, 05/15/09, http:/ / www.podiatry.com/ezines/?pub_year=2009\&section_id=51\#ezine416

[85] Shavelson D: The Tower of Biomechanics; Present Podiatry E-zines 06/26/09, http:/ / www.podiatry.com/ezines / ?pub_year=2009\&section_id=51\#ezine483

[86] Shavelson D: The Common Functional Foot Types: Present Podiatry E-zines,12/05/09, http:/ / www.podiatry.com/ezines/?pub_year=2009\&section_id=51\#ezine541

[87] Shavelson D: The Supine Biomechanical Examination: Present Podiatry E-zines, 02/12/10, http:/ / www.podiatry.com/ezines/ ?pub_year=2010\&section_id=51\#ezine567

[88] Shavelson D: The Functional Foot Typing Forefoot Exam: 03/28/10, http:/ / www.podiatry.com/ezines/?pub_year=2010\&section_id=51\#ezine584

[89] Shavelson D: Biomechanics EBM Part I: Where Does Biomechanics EBM Stand; Present Podiatry zines:

http:/ / www.podiatry.com/ezines/?pub_year=2010\&section_id=51\#ezine603

[90] Shavelson D: Biomechanics EBM Part II: Biomechanics Evidence Based Practice (EBP): Present Podiatry E-zines, 06/28/10, http:/ / www.podiatry.com/ezines/?pub_year=2010\&section_id=51\#ezine678

[91] Shavelson D: Biomechanics EBM Part III: The Levels of Evidence in EBM/EBP: Present Podiatry E-zines, 08/01/10,

http:/ / www.podiatry.com/ezines/?pub_year=2010\&section_id=51\#ezine692

[92] Shavelson D: Current Mainstream Podiatric Biomechanics Part 1: The Science and Current Paradigms; Present Podiatry E-zines, 10/18/10,

http:/ / www.podiatry.com/ezines/?pub_year=2010\&section_id=51\#ezine723

[93] Shavelson D: Rocker Bottom Shoes: A Position Paper, Present Podiatry Ezines, 12/09/10,

http://www.podiatry.com/ezines/?pub_year=2010\&section_id=51\#ezine752

[94] Shavelson D: Wellness Biomechanics Kinesiology and Kinetics, Present Podiatry Ezines, 02/28/11, http:/ / www.podiatry.com/ezines/?pub_year=2011\&section_id=51\#ezine780

[95] Shavelson D: Children's Shoes: A Position Paper, Present Podiatry E-zines, 08/05/11

http:/ / www.podiatry.com/ezines/?pub_year=2011\&section_id=51\#ezine880 
[96] Shavelson D: Plantar Fasciitis, the root of most heel pain; Radius Magazine, p 39-42, Spring 2010

[97] Shavelson D: Neoteric Biomechanics; Podiatry Management, p 123-26, Sept 2008

[98] Shavelson D: Barefoot'n...Did our ancestors have the right technique?; Radius Magazine, 132-34, Winter 2010

.podiatry.com/ezines/?pub_year=2011\&section_id=51\#ezine880 


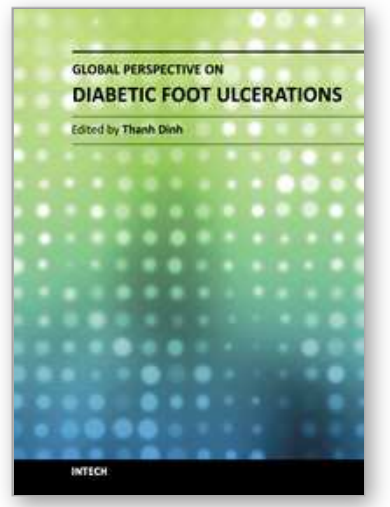

\author{
Global Perspective on Diabetic Foot Ulcerations \\ Edited by Dr. Thanh Dinh
}

ISBN 978-953-307-727-7

Hard cover, 278 pages

Publisher InTech

Published online 09, December, 2011

Published in print edition December, 2011

Over the last decade, it is becoming increasingly clear that diabetes mellitus is a global epidemic. The influence of diabetes is most readily apparent in its manifestation in foot complications across cultures and continents. In this unique collaboration of global specialists, we examine the explosion of foot disease in locations that must quickly grapple with both mobilizing medical expertise and shaping public policy to best prevent and treat these serious complications. In other areas of the world where diabetic foot complications have unfortunately been all too common, diagnostic testing and advanced treatments have been developed in response. The bulk of this book is devoted to examining the newest developments in basic and clinical research on the diabetic foot. It is hoped that as our understanding of the pathophysiologic process expands, the devastating impact of diabetic foot complications can be minimized on a global scale.

\title{
How to reference
}

In order to correctly reference this scholarly work, feel free to copy and paste the following:

Dennis Shavelson (2011). The Biomechanics of the Diabetic Foot, Global Perspective on Diabetic Foot Ulcerations, Dr. Thanh Dinh (Ed.), ISBN: 978-953-307-727-7, InTech, Available from:

http://www.intechopen.com/books/global-perspective-on-diabetic-foot-ulcerations/the-biomechanics-of-thediabetic-foot

\section{INTECH}

open science | open minds

\author{
InTech Europe \\ University Campus STeP Ri \\ Slavka Krautzeka 83/A \\ 51000 Rijeka, Croatia \\ Phone: +385 (51) 770447 \\ Fax: +385 (51) 686166 \\ www.intechopen.com
}

\author{
InTech China \\ Unit 405, Office Block, Hotel Equatorial Shanghai \\ No.65, Yan An Road (West), Shanghai, 200040, China \\ 中国上海市延安西路65号上海国际贵都大饭店办公楼 405 单元 \\ Phone: +86-21-62489820 \\ Fax: +86-21-62489821
}


(C) 2011 The Author(s). Licensee IntechOpen. This is an open access article distributed under the terms of the Creative Commons Attribution 3.0 License, which permits unrestricted use, distribution, and reproduction in any medium, provided the original work is properly cited. 